Journal of Advanced Research in Fluid Mechanics and Thermal Sciences

\title{
On the High-Performance Hydrodynamics Design of a Trimaran Fishing Vessel
}

\author{
Kurniawan Teguh Waskito ${ }^{1}$, Yanuar $^{1, *}$ \\ 1 Department of Mechanical Engineering, Faculty of Engineering, Universitas Indonesia, Depok 16424, Indonesia
}

\begin{tabular}{ll}
\hline ARTICLE INFO & ABSTRACT \\
\hline $\begin{array}{l}\text { Article history: } \\
\text { Received } 26 \text { October } 2020 \\
\text { Received in revised form } 3 \text { April } 2021\end{array}$ & $\begin{array}{l}\text { Trimaran hull form as multihull ship becomes more attractive these days in various ship } \\
\text { types. It offers more advantages in terms of seakeeping performances, particularly on } \\
\text { Accepted } 15 \text { April } 2021\end{array}$ \\
the application of a fishing vessel. However, thus far, the conventional design of fishing \\
vessels is not favorable to ensure the safety of a vessel sailing in a rough sea. In \\
conjunction with such issues, we discuss a trimaran fishing vessel design based on the \\
seakeeping criterion to evaluate the dynamic stability, ship motion RAOs, and ship \\
resistances at the initial design stages using linear strip theory. The intact stabilities are \\
calculated to complement the seakeeping results. The analytical method based on the \\
slender body method is used to evaluate the steady wave resistances. The results of \\
heave, pitch, roll motions, and the ship resistances are discussed. At the zero speed \\
and forward speed, the trimaran shows a favorable motion amplitude, although in \\
forward speeds at the case of head seas there is no significant difference. The trimaran \\
presents a favorable steady-resistance up to the ship speed of Fn=0.27, and it becomes \\
deteriorating than the monohull at higher ship speeds. However, the added wave \\
resistances of the wavelength range 1.0 - 3.0 shows significant added resistances at \\
Fn=0.25 and Fn=0.35, respectively. The results of this study present promising \\
seakeeping and resistance characteristics of the trimaran hull form. The trimaran hull \\
form ensures the safety, reliability, and operation efficiency of ships sailing in broader \\
ranges of violent-sea environment.
\end{tabular}

\section{Introduction}

These days, a multi-hull ship attracts great attention to the shipbuilding industry and academia due to some advantages compared to the conventional monohull ship design. Multi-hull ships are supposed to have more excellent seakeeping performances and better dynamic stability as well as ship resistances to some extent of ship speeds although it has less maneuverability in consequence of the outrigger hull forms. The spacing of outrigger hulls caused the different characteristics of the hydrodynamic performances of the multihull ship [1,2].

The investigation of the resistance components of a displacement catamaran in high speed has been studied by Insel and Molland [3] and better stability of catamaran than monohull was also

\footnotetext{
* Corresponding author.

E-mail address: yanuar@eng.ui.ac.id
}

https://doi.org/10.37934/arfmts.83.1.1733 
studied by Seif and Amini [4]. Moreover, trimaran hull forms are currently of interest due to some advantages in the structural viewpoints and the flexibility of the outrigger hulls compare to catamaran hull forms. Therefore, there are a lot of studies concerning the hydrodynamic performances of trimaran i.e., the seakeeping of a fast trimaran ferry by Boote et al., [5], the resistances, and powering characteristics of a trimaran with the effect of outrigger hull configurations by computation and experiment methods [6-11]. A computation based on the Rankine source method to compute the wave-making resistance of the hull form configurations was studied by Zhang et al., [12], a computation of wave resistance by nonlinear wave-making theory taking into account the trim and sink was studied by Wang and Lu [13], and a numerical study to optimize the resistance of side hull of trimaran was conducted by Xu and Zhang [14]. However, to date, the studies on the seakeeping characteristics of trimaran are not as much as resistances. Therefore, more researches concerning the ship motion RAOs and stabilities of trimaran are intriguing to be conducted.

In the application of a fishing vessel, the critical issue is related to the seakeeping performances in conjunction with the safety at sea and the Motion Sickness Index to the crews. However, more study of the hydrodynamic characteristics such as the stability and resistance performances are also critical. Up to date, there are still a few numbers of the development of multi-hull fishing vessels to deal with such issues. In this paper, we aim to study the seakeeping, stability, and resistance performances of a trimaran fishing vessel in comparison to a monohull fishing vessel at the initial design stages. The trimaran was designed as a semi trimaran hull form to enable computation of the sectional interpolation in the strip theory frameworks. The popular seakeeping computation, linear strip theory method introduced by Salvesen et al., [15] was used in this paper. The linear strip theory method was used to compute the ship motion RAOs and the added resistances with respect to the computation efficiency. The intact stabilities of large-angle stabilities are calculated to complement the seakeeping characteristics. The analytical slender body method of wave pattern resistances is also made in this study to calculate the steady calm water resistances. The commercial program MAXSURF motions, stabilities, and resistances are used in this study with the validation that has been made by some comparison with other computation programs and experimental data [16-18].

\section{Formulation and Computation Methods}

In this section, the well-known linear strip potential theory method, originally developed in the 1970 s by Salvesen et al., [15] is applied for many applications, unlike more advanced methods, it is relatively simple to use and efficient in the viewpoint of computational cost. Strip theory is a frequency-domain method. The ship is divided into a number of transverse sections. Each section presents a two-dimensional section to compute its hydrodynamic coefficients. The hydrodynamic coefficients at each section are then integrated along the ship hull length to get the global coefficients of the ship's equation of motion. In this paper, we consider only some significant motion RAOs such as coupling of heave and pitch and the uncoupled roll motion by using MAXSURF motions Version 20 [16].

Some underlying assumption of the linear strip theory when calculating the ship motions are inviscid flow, slender ship, rigid hull, moderate range of speed, motion amplitudes are relatively small with respect to the wave amplitude, deep-water wave approximations, and disturbances of incident wave are neglected (Froude-Krylov assumption).

The strip theory method has been validated by various sources of public data i.e., Bishop et al., [19] for the algorithms of the two-dimensional section hydrodynamic coefficients and Skejic for the strip theory method of maneuvering and seakeeping of a single ship and of two ships in interaction [20]. The heave and pitch responses have been validated by some model and full-scale vessels i.e., 
catamaran vessel by Wellicome et al., [21], Series 60 by Gerritsma [22], and also a nonlinear timedomain program, SWAN program Sclavounos et al., [23]. The roll motion is validated against a commercial program ANSYS AQWA for a catamaran model and the solver proposed by Ghamari et al., [24] investigating the roll motions of container carrier ships. In addition, the added resistance has also been validated with the SA van der Stel, a fast freight vessel by Journée [25]. Overall, MAXSURF motions predict heave, pitch, and roll motions in a reliable agreement and the added resistance with sufficient quality for comparative hull form analysis.

\subsection{Calculation of Coupled Heave and Pitch Motions}

Under the assumption that the ship motions are linear and harmonic with a slender hull form the coupled equations of motion for heave and pitch can be written in the form [15]

$$
\begin{aligned}
& \left(M+A_{33}\right) \ddot{\eta}_{3}+B_{33} \dot{\eta}_{3}+C_{33} \eta_{3}+A_{35} \ddot{\eta}_{5}+B_{35} \dot{\eta}_{5}+C_{35} \eta_{5}=F_{3} e^{i \omega_{e} t} \\
& \left(I_{5}+A_{55}\right) \ddot{\eta}_{5}+B_{55} \dot{\eta}_{5}+C_{55} \eta_{5}+A_{53} \ddot{\eta}_{3}+B_{53} \dot{\eta}_{3}+C_{53} \eta_{3}=F_{5} e^{i \omega_{e} t}
\end{aligned}
$$

Where $M$ is mass of the ship, $I_{5}$ moment inertia for pitch, $A_{33}$ added mass coefficient of the heave due to heave, $A_{55}$ added mass coefficient of the pitch due to pitch, $A_{35}$ added mass coefficient of the heave due to pitch, $A_{53}$ added mass coefficient of the pitch due to heave, $B_{33}$ damping coefficient of the heave due to heave, $B_{55}$ damping coefficient of the pitch due to pitch, $B_{35}$ damping coefficient of the heave due to pitch, $B_{53}$ damping coefficient of the pitch due to heave, $C_{33}$ static restoring coefficient of the heave due to heave, $C_{55}$ static restoring coefficient of the pitch due to pitch, $C_{35}$ static restoring of the heave due to pitch, $C_{53}$ static restoring coefficient of the pitch due to heave, $F_{3}$ heave exciting force, $F_{5}$ pitch exciting force, $\eta_{3}$ instantaneous heave displacement, $\dot{\eta}_{3}$ instantaneous heave velocity, $\ddot{\eta}_{3}$ instantaneous heave acceleration, $\eta_{5}$ instantaneous pitch displacement, $\dot{\eta}_{5}$ instantaneous pitch velocity, $\ddot{\eta}_{5}$ instantaneous pitch acceleration. To solve Eq. (1) and Eq. (2) it is necessary to obtain the coefficients and excitation of force and moment. The added mass and damping coefficient taking into account the transom section are as follows

$$
\begin{aligned}
& A_{33}=\int a_{33} d \xi-\frac{U}{\omega^{2}} b_{33}^{A} \\
& B_{33}=\int b_{33} d \xi+\frac{U}{\omega^{2}} a_{33}^{A} \\
& A_{35}=-\int \xi a_{33} d \xi-\frac{U}{\omega^{2}} B_{33}^{0}+\frac{U}{\omega^{2}} x_{A} b_{33}^{A}-\frac{U^{2}}{\omega^{2}} a_{33}^{A} \\
& B_{35}=-\int \xi b_{33} d \xi-U A_{33}^{0}+U x_{A} a_{33}^{A}-\frac{U^{2}}{\omega^{2}} b_{33}^{A} \\
& A_{53}=-\int \xi a_{33} d \xi+\frac{U}{\omega^{2}} B_{33}^{0}+\frac{U}{\omega^{2}} x_{A} b_{33}^{A}
\end{aligned}
$$


$B_{53}=-\int \xi b_{33} d \xi-U A_{33}^{0}-U x_{A} a_{33}^{A}$

$A_{55}=\int \xi^{2} a_{33} d \xi+\frac{U^{2}}{\omega^{2}} a_{33}^{0}-\frac{U}{\omega^{2}} x_{A}^{2} b_{33}^{A}+\frac{U^{2}}{\omega^{2}} x_{A} a_{33}^{A}$

$B_{55}=\int \xi^{2} b_{33} d \xi+\frac{U^{2}}{\omega^{2}} b_{33}^{0}+U x_{A}^{2} a_{33}^{A}+\frac{U^{2}}{\omega^{2}} x_{A} b_{33}^{A}$

Where $a_{33}$ is section added mass, $b_{33}$ section damping, $a_{33}^{A}$ added mass of transom section, $b_{33}^{A}$ damping of transom section, $\omega$ wave encounter of circular frequency, $U$ ship forward speed. All the integrals are over the length of the ship. The hydrostatic restoring coefficients are independent of frequency and forward speed described as follows

$C_{33}=\rho g \int b d \xi=\rho g A_{W P}$

$C_{35}=C_{53}=-\rho g \int b d \xi=-\rho g M_{W P}$

$C_{55}=\rho g \int \xi^{2} b d \xi=\rho g I_{W P}$

where $b$ is section beam, $g$ acceleration due to gravity, $\rho$ fluid density, $A_{W P}, M_{W P}$, and $I_{W P}$ are the area, moment and the moment inertia of the water plane. The wave exciting force and moment for arbitrary heading can be described as follows

$$
\begin{aligned}
& F_{3}=\rho \alpha \int\left(f_{3}+h_{3}\right) d \xi+\rho \alpha \frac{U}{i \omega} h_{3}^{A} \\
& F_{5}=-\rho \alpha \int\left[\xi\left(f_{3}+h_{3}\right)+\frac{U}{i \omega} h_{3}\right] d \xi-\rho \alpha \frac{U}{i \omega} x_{A} h_{3}^{A} \\
& f_{3}(x)=g e^{-i k x \cos \beta} \int_{C_{x}} n_{3} e^{i k y \sin \beta} e^{k z} d l \\
& h_{3}(x)=\omega_{0} e^{-i k x \cos \beta} \int_{C_{x}}\left(i n_{3}-n_{2} \times \sin \beta\right) e^{i k y \sin \beta} e^{k z} \psi_{3} d l
\end{aligned}
$$

Here, $f_{3}$ sectional Froude-Krilov force, $h_{3}$ sectional Diffraction force, $h_{3}^{A}$ sectional diffraction force of the transom section, $x_{A}$ is $\mathrm{x}$ ordinate of transom (from CoG, negative aft.), $\alpha$ the wave amplitude, $k$ the wavenumber, $\beta$ the incident wave angle as shown in the coordinate system in Figure $1, d l$ is an element along the cross-section $C_{x}, \omega_{0}$ the incident wave frequency, $n_{2}$ and $n_{3}$ are the components in the $y$ and $z$ directions of the two-dimensional normal vector, and $\psi_{3}$ the radiation velocity potential for two-dimensional problem. 
The coefficients and the excitation in Eq. (1) and Eq. (2) are eventually obtained from the integration over the length of the ship once the sectional added mass, damping, and velocity potential are known.

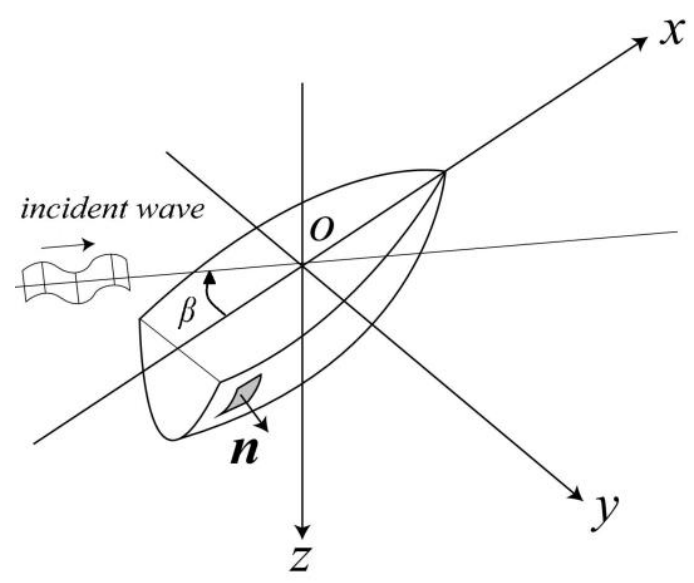

Fig. 1. Coordinate system and definition of incident-wave direction of the Strip theory method

\subsection{Calculation of Uncoupled Roll Motion}

$\left(I_{4}+A_{44}\right) \ddot{\eta}_{4}+B_{44} \dot{\eta}_{4}+C_{44} \eta_{4}=F_{4} e^{i \omega_{e} t}$

$I_{4}, A_{44}, B_{44}, C_{44}$ are moment inertia, added mass, damping coefficient, and the static restoring coefficient for roll, respectively. $F_{4}, \eta_{4}, \dot{\eta}_{4}, \ddot{\eta}_{4}$ are roll exciting moment, instantaneous displacement, velocity, and acceleration of roll, respectively. Comparison between theory and experiments shows that roll-damping coefficient is significantly affected by viscosity even in the absence of bilge keels, hence the amplitude of the roll displacement should be computed by taking into account the viscous roll damping by Vugts [26,27]

$$
\begin{aligned}
& A_{44}=\int a_{44} d \xi-\frac{U}{\omega^{2}} b_{44}^{A} \\
& B_{44}=\int b_{44} d \xi+U a_{44}^{A}+B_{44}^{*}
\end{aligned}
$$

where $a_{44}$ and $b_{44}$ are the sectional added mass and damping in roll, $a_{44}^{A}$ and $b_{44}^{A}$ are the added mass and damping coefficient of the transom section. $B_{44}^{*}$ represents quasi-linear viscous-damping effects in the roll. It has been computed by equations derived by Kato [28] for skin friction and Tanaka [29] for eddy-making resistance recommended

$$
B_{44}^{*}=K \dot{\eta}_{4 \max }
$$


where $K$ depends on the frequency, the viscosity, the bilge-keel dimensions, and the hull geometry, $\dot{\eta}_{4 \max }$ is the maximum roll velocity and must be of iterative value. The hydrostatic restoring coefficient is as follow

$$
C_{44}=\rho g \nabla \overline{G M}
$$

where $\nabla$ is the displaced volume of the ship, $\overline{G M}$ is the metacentric height. The amplitude of the roll exciting moment is

$$
F_{4}=\alpha \rho \int\left(f_{4}+h_{4}\right) d \xi+\alpha \rho \frac{U}{i \omega} h_{4}^{A}
$$

where the sectional Froude-Krilov and Diffraction forces are

$$
\begin{aligned}
& f_{4}(x)=g e^{-i k x \cos \beta} \int_{C_{x}} n_{4} e^{i k y \sin \beta} e^{k z} d l \\
& h_{4}(x)=\omega_{0} e^{-i k x \cos \beta} \int_{C_{x}}\left(i n_{3}-n_{2} \times \sin \beta\right) e^{i k y \sin \beta} e^{k z} \psi_{4} d l
\end{aligned}
$$

Eventually, the coefficients and excitation in Eq. (18) are solved in the same manner as solving the coupling of heave and pitch by integrating the sectional coefficients along the ship length.

\subsection{Calm Water Resistance}

A slender body method by Tuck et al., [30] and Couser [31]. This method uses a Michell based approach, an analytical method to compute the wave resistance of a port/starboard symmetrical monohull [32].

This method may be applied to various hull forms including multihull as long as the hull is slender of around 5.0 to 6.0. In this study both the trimaran and monohull have slenderness ratios of 5.75. Transom stern is considered in the calculation. Planing forces are neglected in the slender body method which limits speed range applicability. This method predicts only the wave pattern resistance component. To calculate the total resistance, MAXSURF Resistance incorporates the viscous resistance component using the ITTC'57 friction coefficient calculation method and the specified form factor. The appendage and air resistance for the superstructures are considered in the boundary condition, too. The total calm water resistance may be written as follow

$$
\begin{aligned}
& R_{T}=R_{W}+R_{V}+R_{A p p}+R_{A i r} \\
& R_{V}=(1+k) R_{F}
\end{aligned}
$$

where $R_{T}, R_{W}, R_{V}, R_{A p p}, R_{A i r}$ are total, wave, viscous appendage, and air resistances, $k$ and $R_{F}$ are form factor and friction resistance, respectively.

The slender body method has been compared with some theoretical methods and experiments i.e., by using a Wigley hull by Insel and Molland [3] and NPL round-bilge model by Couser [31] for the 
validation of incorporating the transom stern. The results of validation were in a favorable agreement.

\subsection{Added Wave Resistances}

Added wave resistance calculations are second order with respect to wave amplitude and are based on the calculated motions. This means that if motions are calculated with an accuracy of approximately $10-15 \%$, the accuracy of the added resistance calculation will be no better than 20 $30 \%$ [33]. The Salvesen method is based on calculating the second-order longitudinal wave force acting on the vessel. Theoretically, this method may also be applied to oblique waves. The methods are only applicable to head seas and are calculated only from the heave and pitch motions. The added resistance calculated is due only to the motion of the vessel in the waves. Thus, MAXSURF motions commercial program was used to calculate the added resistance. It does not account for speed loss due to wind; reduction of propeller efficiency or voluntary speed loss in order to reduce motions. The added resistance, $R_{A W}$, can be obtained from the following [33]

$R_{A W}=\frac{i k}{2}\left(\eta_{3} \hat{F}_{3}+\eta_{5} \hat{F}_{5}\right)+R_{7}$

where

$$
\begin{aligned}
& \hat{F}_{3}=\zeta \int_{L} e^{-i k \xi} e^{-k z}\left[c(\xi)-\omega_{0}\left(\omega a_{33}(\xi)\right)-i b_{33}(\xi)\right] d \xi \\
& \hat{F}_{5}=-\zeta \int_{L} e^{-i k \xi} e^{-k z}\left[c(\xi)-\omega_{0}\left(\xi+\frac{i U}{\omega}\right)\left(\omega a_{33}(\xi)\right)-i b_{33}(\xi)\right] d \xi
\end{aligned}
$$

and

$R_{7}=\frac{\zeta^{2} k \omega_{0}^{2}}{2 \omega} \int_{L} e^{-2 k z} b_{33}(\xi) d \xi$

$\eta_{3}$ and $\eta_{5}$ are the complex heave and pitch amplitudes, containing both phase and amplitude values.

\subsection{Computational Domain}

In this study, the trimaran fishing vessel was designed in full scale as shown in Figure 2 and Table 1. Although the full-scale ship design includes the superstructure, however, in the seakeeping computation only the hull under waterline was being taken into account. The computation of fullscale trimaran was conducted to assess the seakeeping data of heave, pitch, and roll motions as well as the resistance data in calm water and in wave conditions. The seakeeping computation was conducted with a range of regular wavelengths of $\lambda / L=0.5 ; 0.8 ; 1 ; 1.2 ; 1.5 ; 1,7 ; 2 ; 2.5 ; 3 ; 3.5$ for the cases of the head sea and following sea. In the head sea and following sea the ship speeds were set of $\mathrm{Fn}=0, \mathrm{Fn}=0.25$ (service speed), and $\mathrm{Fn}=0.35$ (maximum speed). For the case of quarter, beam and 
bow seas, the range of wavelength of $\lambda / L=0.5 ; 0.8 ; 1 ; 1.2 ; 1.5 ; 1,7 ; 2 ; 2.5 ; 3 ; 3.5 ; 4.5 ; 6$ with the ship speed at $\mathrm{Fn}=0.25$. In the quarter, beam, and bow seas, the encountered wave angles were 45 deg., 90 deg., and 135 deg. Ship resistances experiment was conducted in calm water to obtain the total resistance (steady resistance) with a speed range of $\mathrm{Fn}=0.1 ; 0.16 ; 0.2 ; 0.23 ; 0.25 ; 0.28 ; 0.3$; $0.35 ; 0.4 ; 0.45$. For the added wave resistances, the ship speeds were at $\mathrm{Fn}=0.25$ and $\mathrm{Fn}=0.35$ with the wavelengths of $\lambda / L=0.5 ; 0.8 ; 1 ; 1.2 ; 1.5 ; 1,7 ; 2 ; 2.5 ; 3 ; 3.5 ; 4.5 ; 6$. The monohull model was used to compare the hydrodynamic characteristics of the trimaran model with similar ship particulars as shown in Table 1, mainly the displacement, the vertical center of gravity, and the gyration radius of inertia as shown in Figure 3.

Table 1

Main particulars of the fishing vessel

\begin{tabular}{ll}
\hline & Full scale \\
\hline Displacement $(\mathrm{kg})$ & 104,000 \\
Length, LWL $(\mathrm{m})$ & 28.37 \\
Breadth, B $(\mathrm{m})$ & 4.93 \\
Draft, T $(\mathrm{m})$ & 1.25 \\
KB $(\mathrm{m})$ & 0.78 \\
KG $(\mathrm{m})$ & 2.54 \\
Block coeff. $(\mathrm{Cb})$ & 0.58 \\
Roll gyradius, Kxx $(\mathrm{m})$ & 2 \\
Pitch gyradius, Kyy $(\mathrm{m})$ & 7.83 \\
Yaw gyradius, Kzz $(\mathrm{m})$ & 7.83 \\
Length:Beam ratio & 5.76 \\
Beam:Draft ratio & 3.94 \\
\hline
\end{tabular}

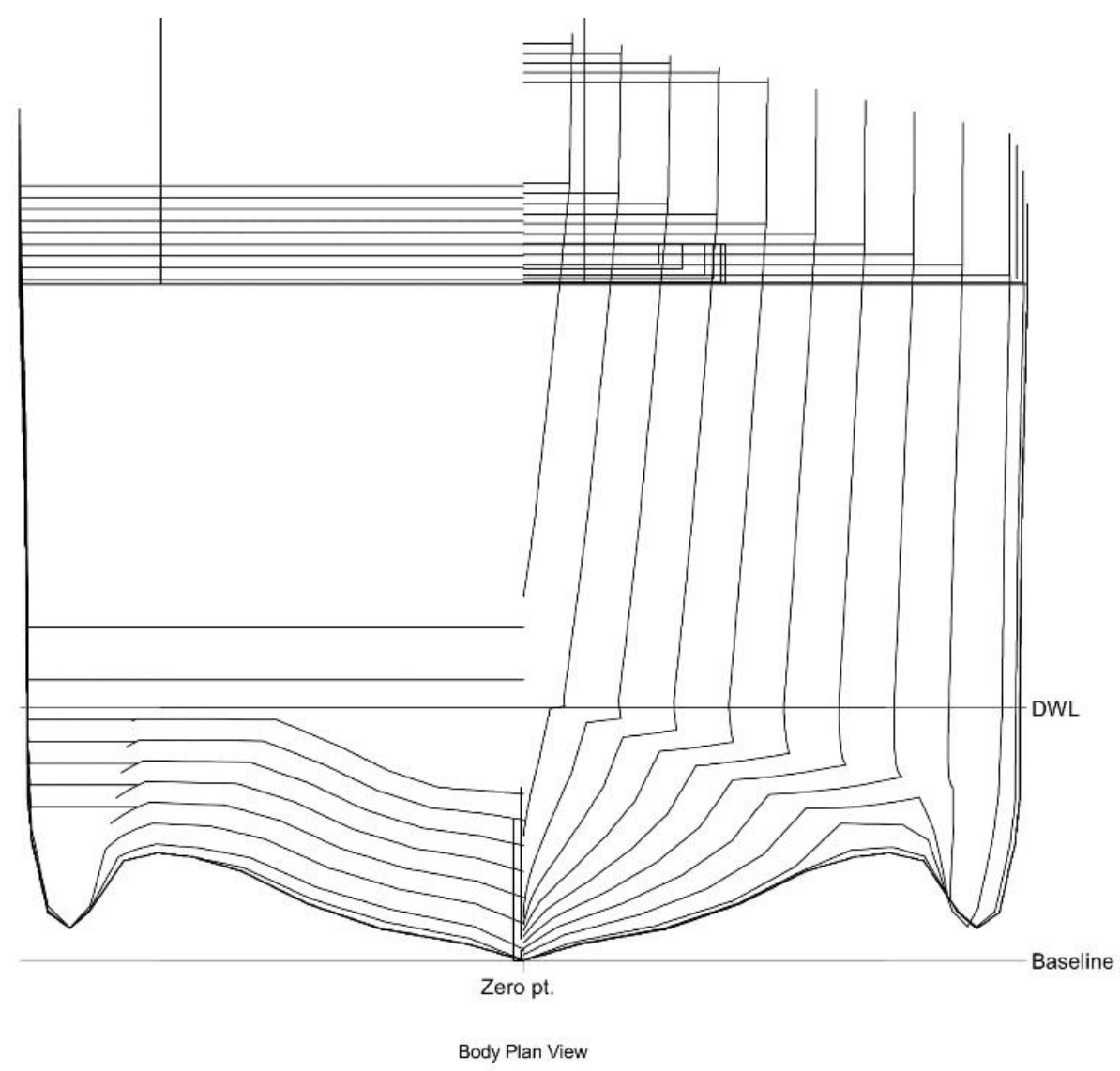

(a) 


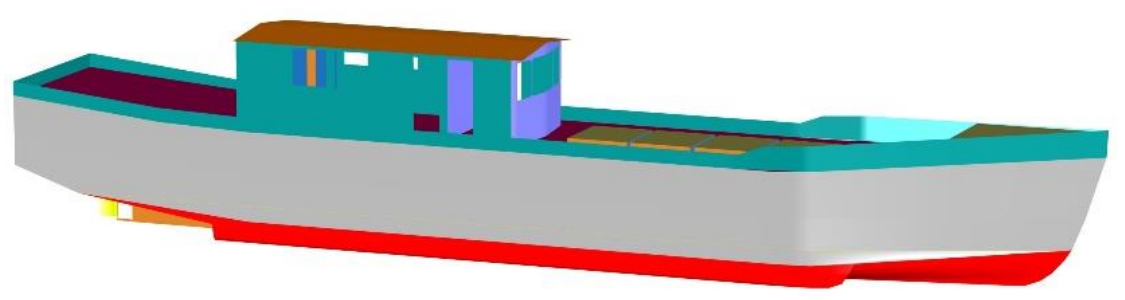

(b)

Fig. 2. Full scale trimaran fishing vessel, (a) body plan of the trimaran fishing vessel, (b) isometric view of the full-scale trimaran fishing vessel

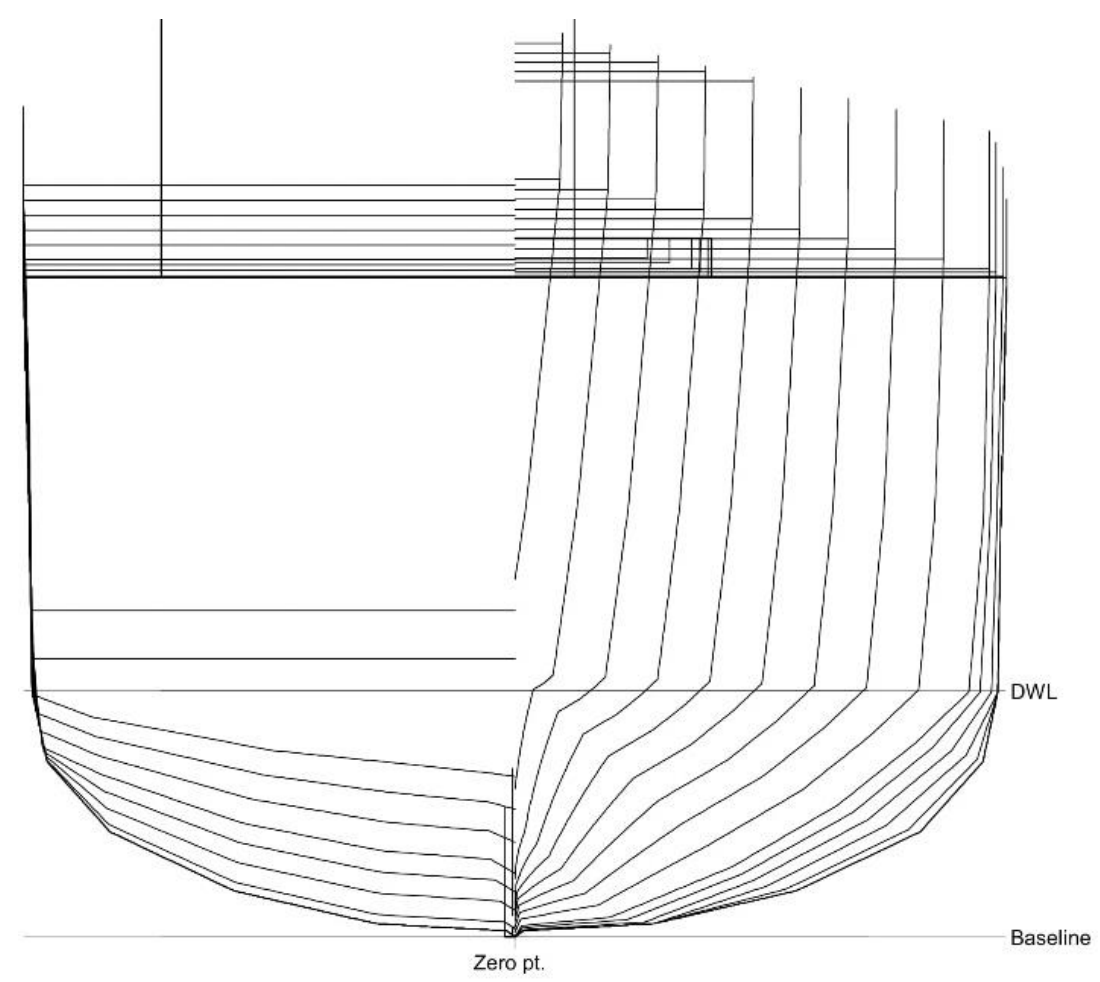

(a)

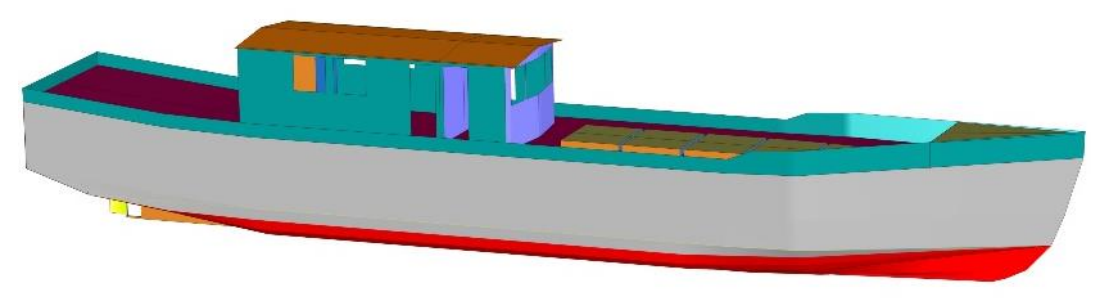

(b)

Fig. 3. Full scale monohull fishing vessel, (a) body plan of the monohull fishing vessel, (b) isometric view of the full-scale monohull fishing vessel

\section{Results and Discussion}

The results are discussed in this section by comparing the computations of trimaran and monohull. The ship intact stabilities, ship motion RAOs, and ship resistances are discussed in the following subsections. 


\subsection{Ship Intact Stabilities}

In this section, we consider the intact stability curve as shown in Figure 4 to understand the initial stability characteristics of the trimaran and monohull models and the dependencies of the hull geometry. Both models have the vertical center of gravity at $2.54 \mathrm{~m}$ with the same displacement, load case, and trim condition. Nonetheless, in this condition we note the initial metacentric height between the two models was slightly different, $0.47 \mathrm{~m}$ and $0.44 \mathrm{~m}$ for the trimaran and monohull model, respectively. As shown in Figure 4(a), the maximum GZ is $0.173 \mathrm{~m}$ at $23.6 \mathrm{deg}$. for trimaran and $0.098 \mathrm{~m}$ at $21.8 \mathrm{deg}$. for monohull. The point of vanishing stability is $60 \mathrm{deg}$. for both models. Despite the slightly different in the initial metacentric height, however, with respect to the effect of different geometry, we can understand that the trimaran model has better static stability than the monohull model as shown in Figure 4(b) with the larger GZ maximum as well as the total area under GZ-curve. A large GZ-length difference of almost twice from the monohull showing much better initial-stability of the trimaran. In other words, the amount of energy that the trimaran can absorb from external heeling forces until capsize is larger than the monohull model.

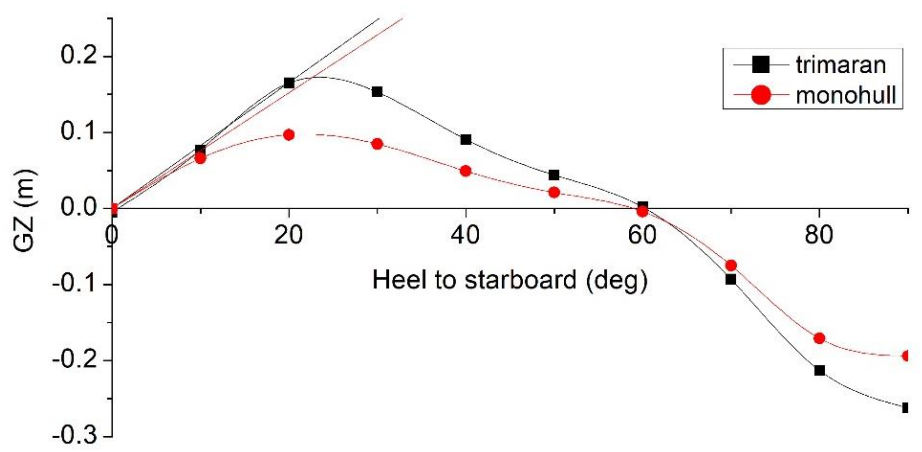

(a)

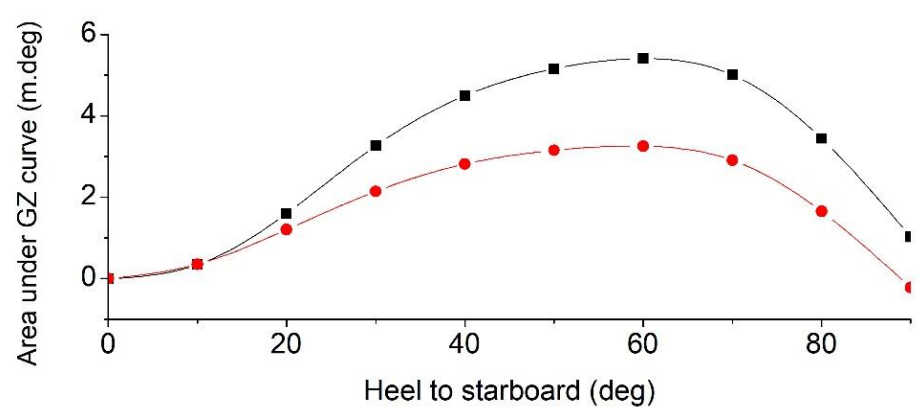

(b)

Fig. 4. Static stability curve, (a) GZ-curve, (b) Total area under GZ-curve

\subsection{Ship Motions}

In this study, we consider the three different ship speeds, $F n=0 ; 0.25$; and 0.35 for the cases of head and following seas as shown in Figure 5 to Figure 10. These symmetric motions of heave and pitch are important not only for seakeeping but also for further analysis of the added resistances and wave loads of the vertical bending moment although wave loads are not covered in this study. The results of heave and pitch are presented in non-dimensional values with the amplitudes are normalized with the incident wave amplitude for heave and pitch also with the wavenumber for 
pitch. The incident wave height was within the framework of linear theory with the wave steepness, $H / \lambda \leq 1 / 30$.

The results of zero speed, $\mathrm{Fn}=0.0$ as shown in Figure 5 and Figure 6 , the computation at zero speed is relatively easier and in a good trend for both the following and head seas. It is obvious that the trimaran shows a lower amplitude of heave and become much lower different for pitch than the monohull.
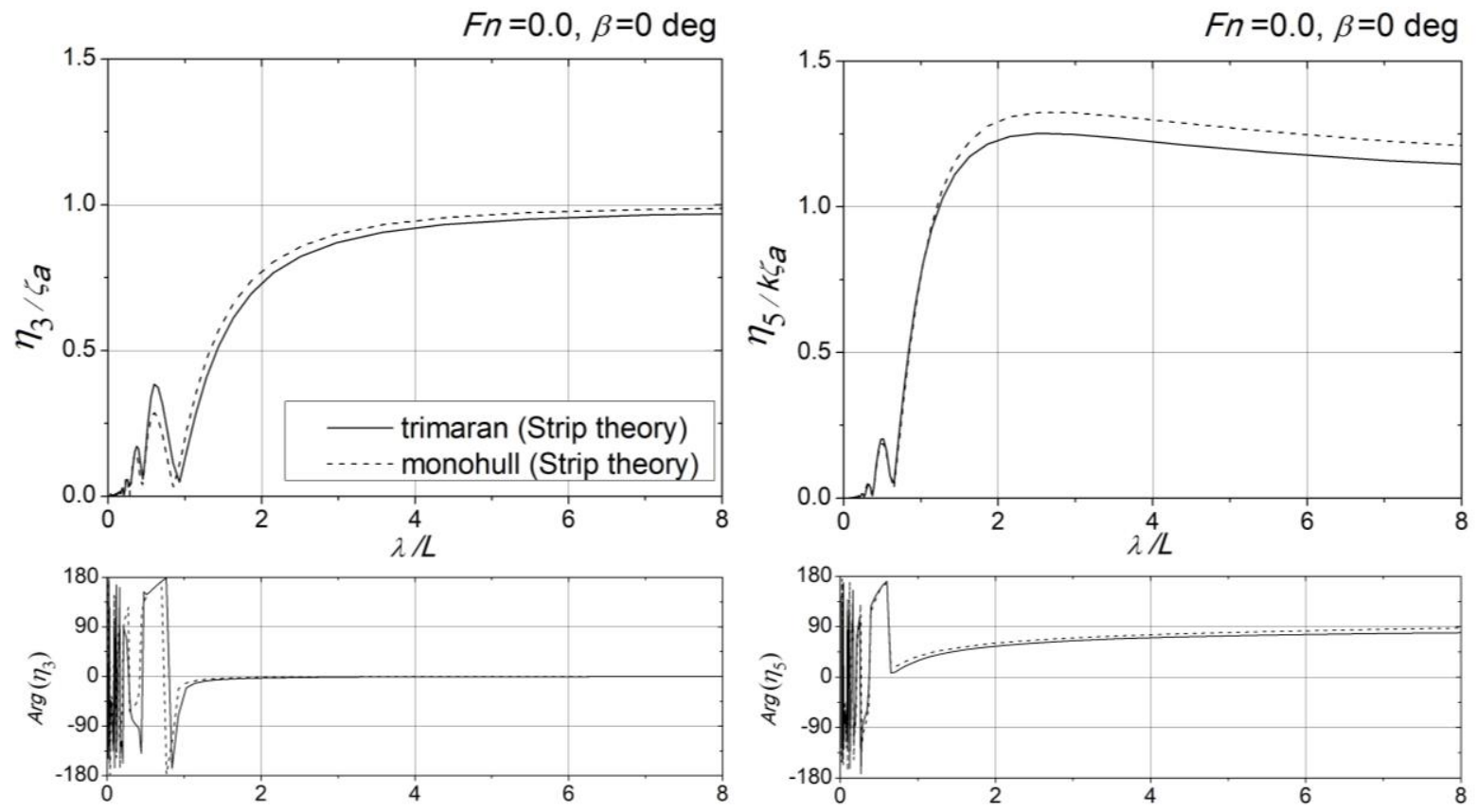

Fig. 5. Heave and pitch RAOs of the trimaran and monohull at $\mathrm{Fn}=0.0$ in following seas
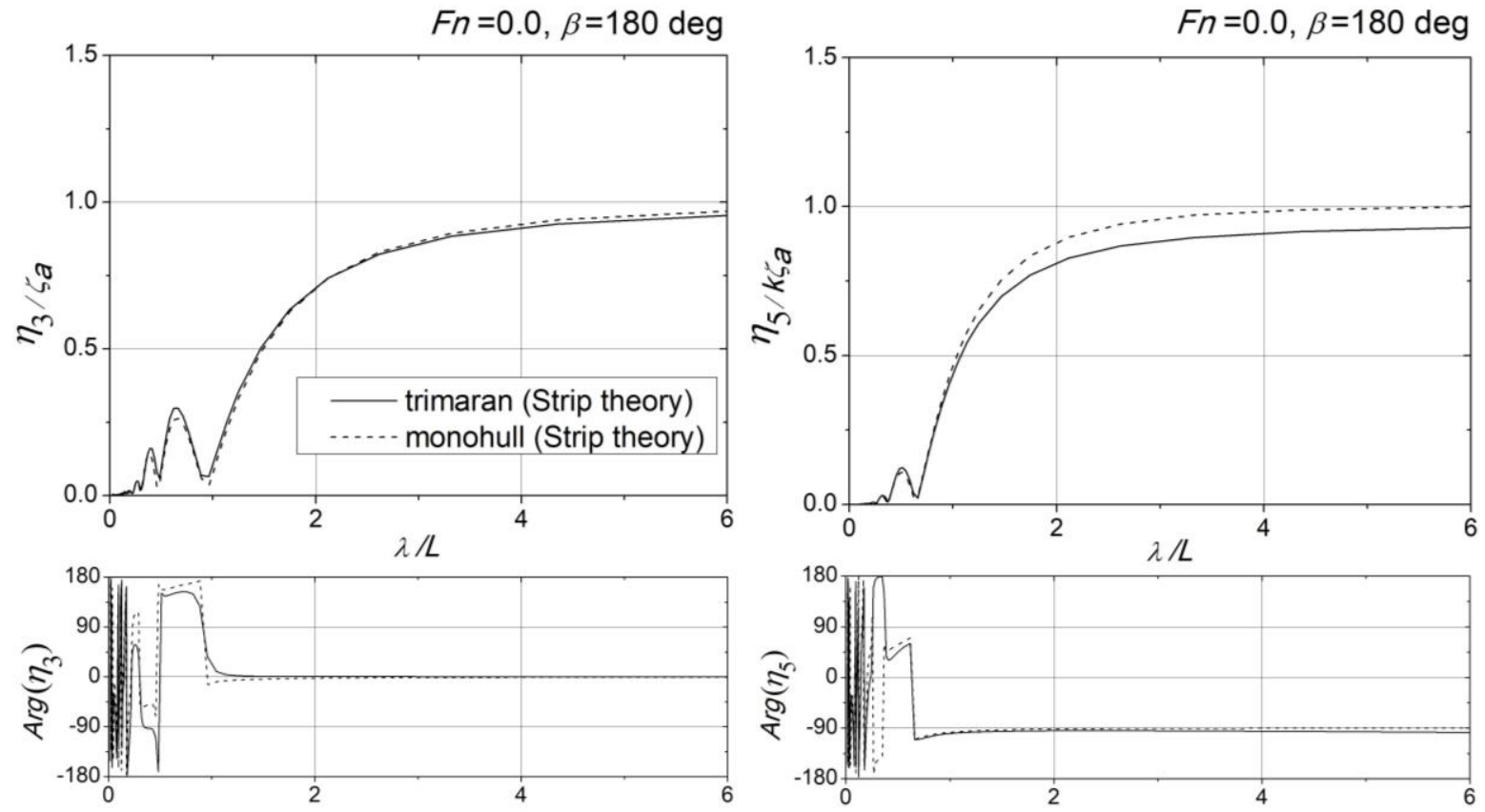

Fig. 6. Heave and pitch RAOs of the trimaran and monohull at $\mathrm{Fn}=0.0$ in head seas 
For the case of forward speed, at $F n=0.25$ as shown in Figure 7 and Figure 8, the computation is not straightforward particularly the accuracy in short wavelengths. For the following sea condition, the trimaran shows slightly better than the monohull in heave amplitude and much lower in pitch amplitude. For the head sea condition, it is important to notice the motion amplitude in the resonance frequencies around $\lambda / L=1.0-1.5$. Although we should note that due to the linear theory limitation it should be some larger discrepancies with the real condition compare to the other frequency ranges. Therefore, it seems to be more difficult to get a comparison between the trimaran and monohull in the case of the head sea.
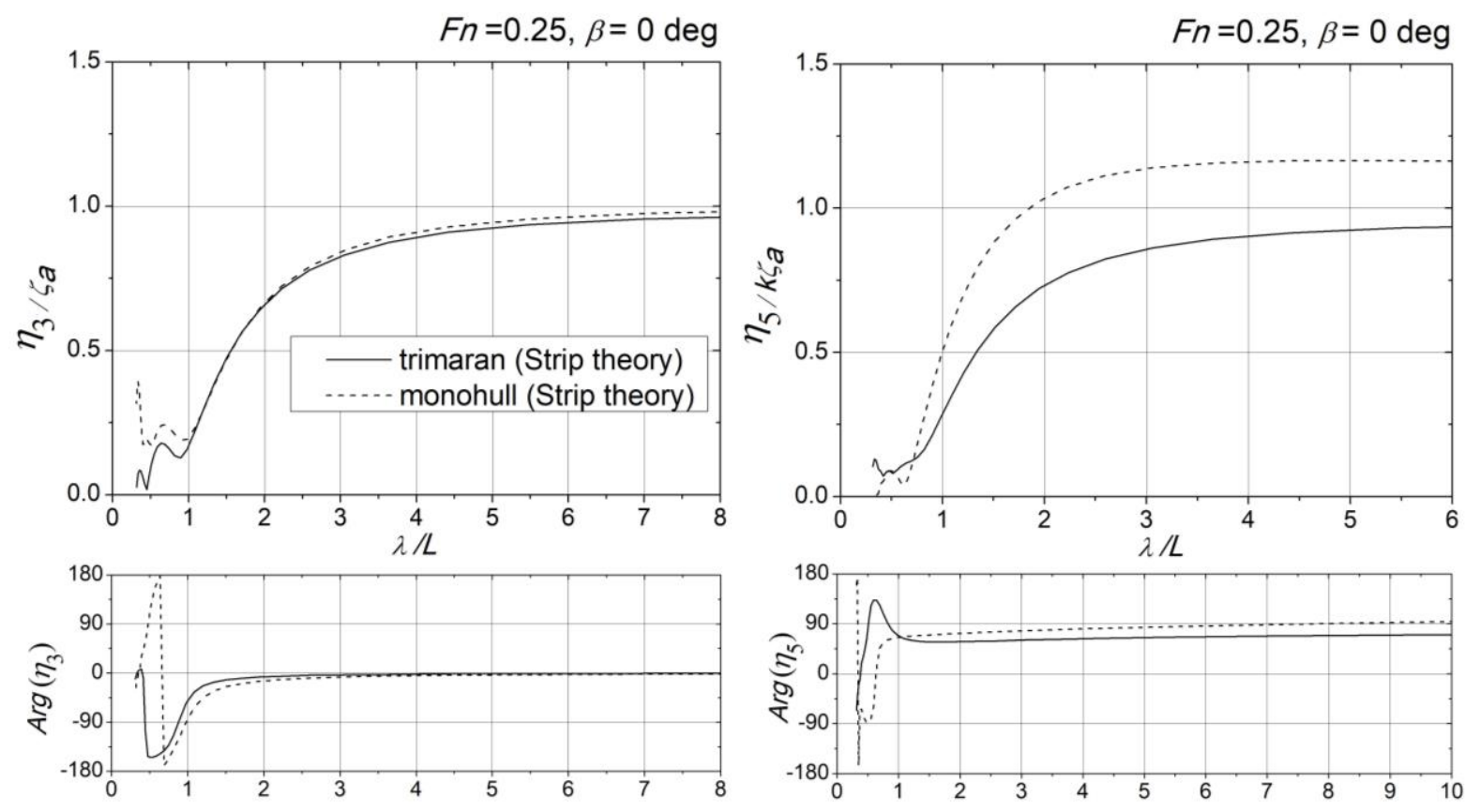

Fig. 7. Heave and pitch RAOs of the trimaran and monohull at $F n=0.25$ in following seas
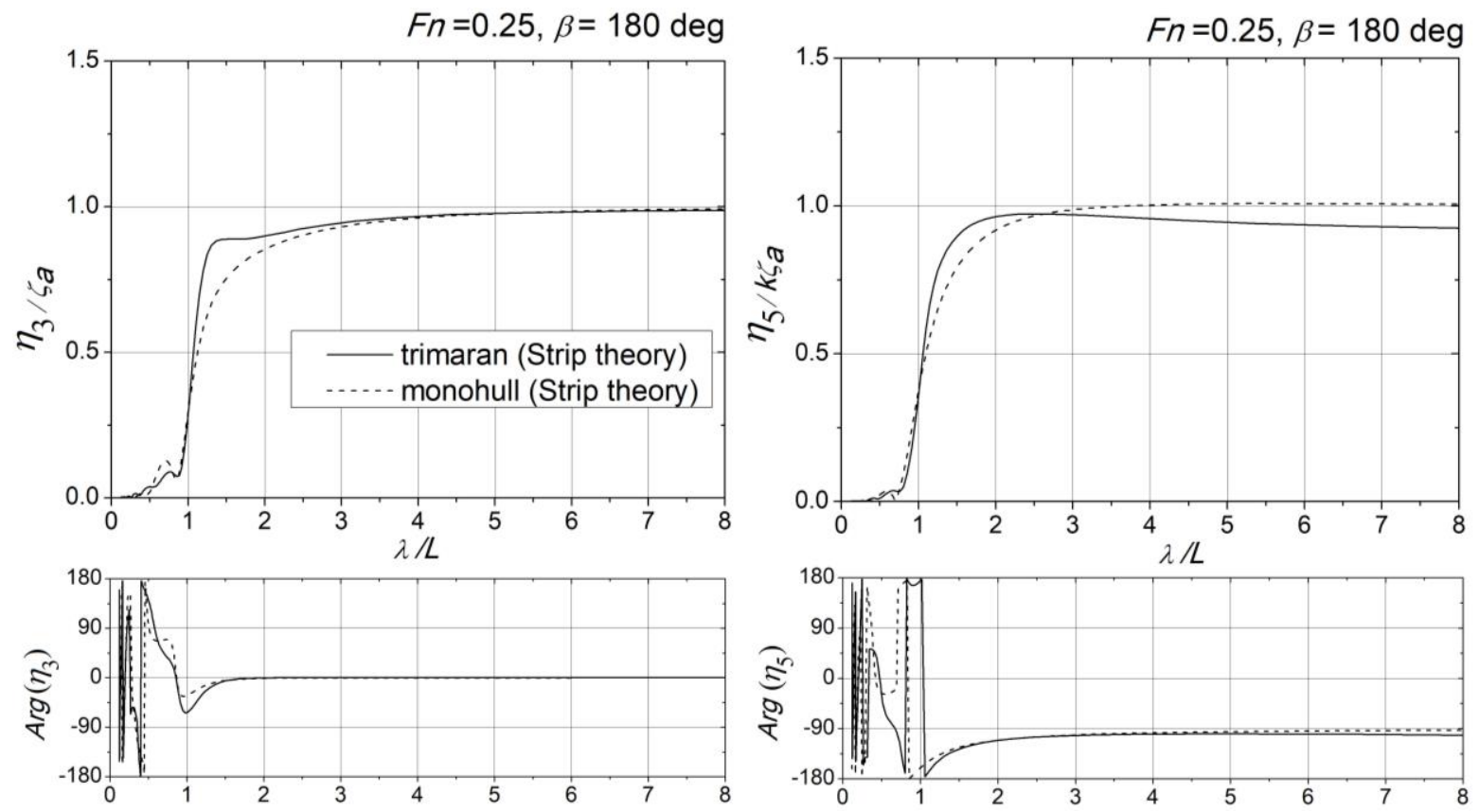

Fig. 8. Heave and pitch RAOs of the trimaran and monohull at $\mathrm{Fn}=0.25$ in head seas 
For the case of larger forward speed, $\mathrm{Fn}=0.35$ as shown in Figure 9 and Figure 10, the tendency of results is similar to the case of $F n=0.25$. However, the large difference for the pitch amplitudes from both forward speed in the following sea conditions should be noted for further comparison to assess the accuracy of the computation with other computation methods i.e., panel methods, CFD, or with experiment. Similar results are also observed in head sea conditions with the case of $\mathrm{Fn}=0.25$. The trimaran seems to be worse than the monohull in this case for the heave and pitch amplitudes, particularly in resonance frequencies.
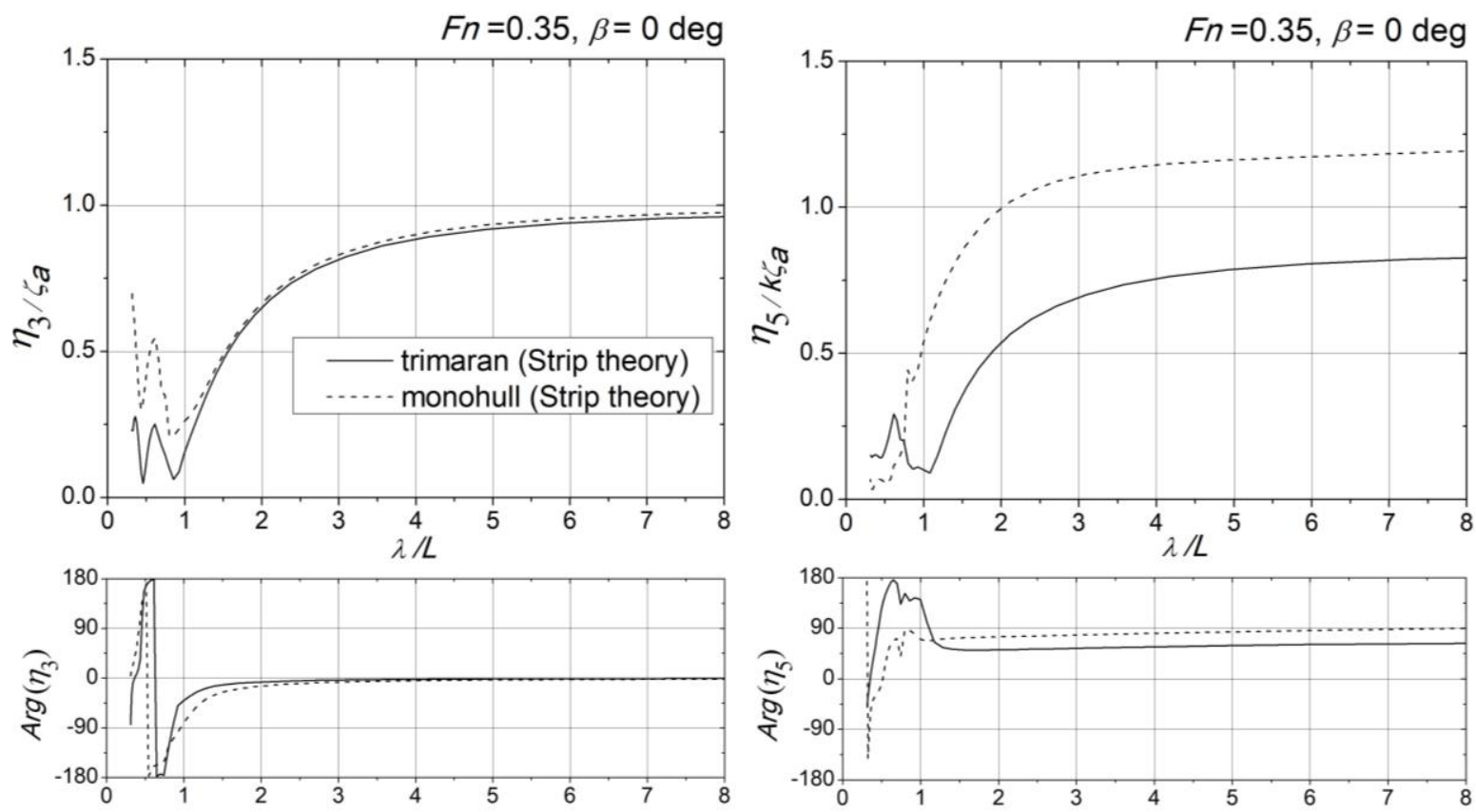

Fig. 9. Heave and pitch RAOs of the trimaran and monohull at $F n=0.35$ in following seas
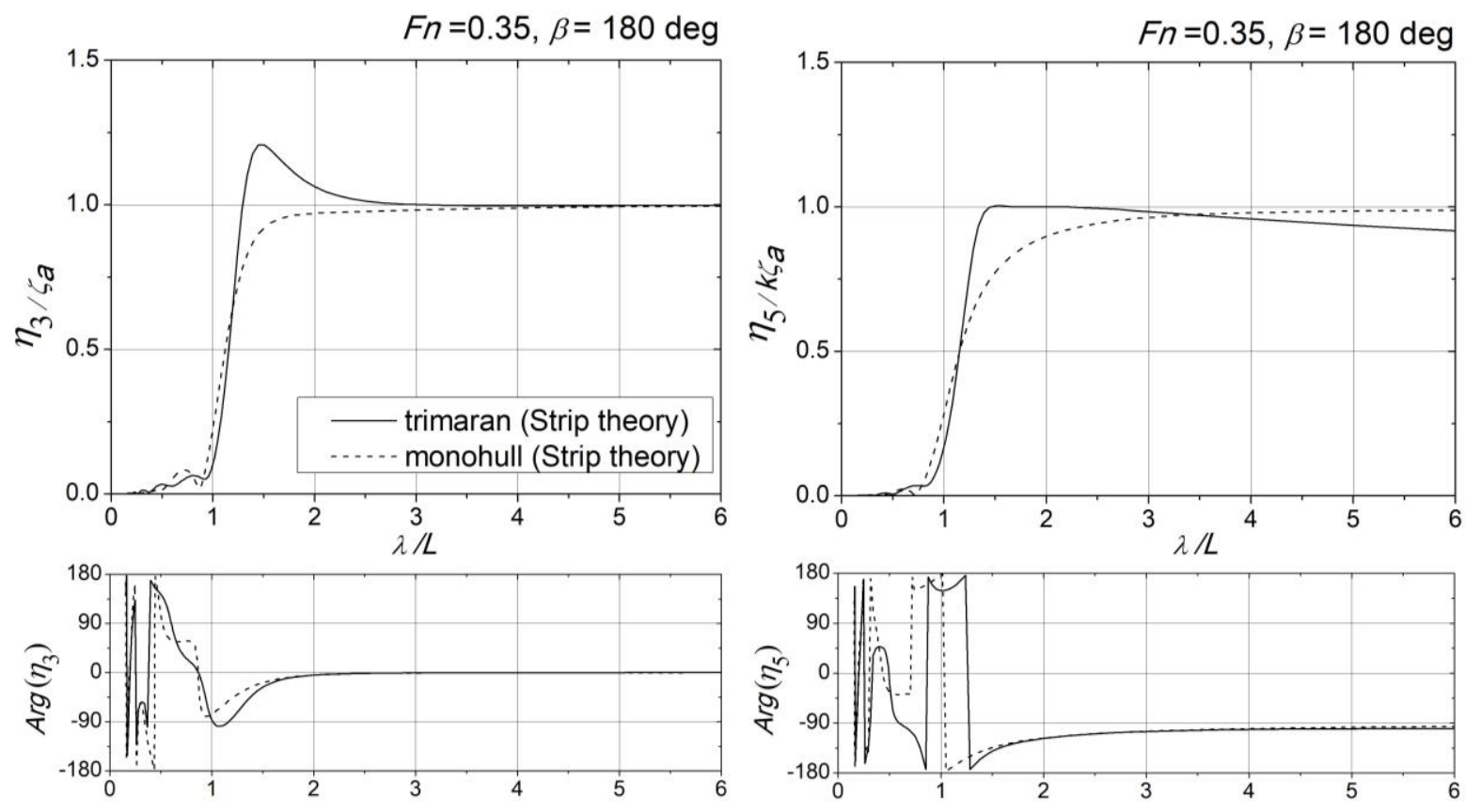

Fig. 10. Heave and pitch RAOs of the trimaran and monohull at $\mathrm{Fn}=0.35$ in head seas 
The roll motion RAOs are computed for forward speed case, $\mathrm{Fn}=0.25$ in the case of the quarter, beam, and bow seas as shown in Figure 11 . The viscous damping ratio, $B_{44}^{*}$, is applied in the computation based on the ship speed. From Figure 11 we can see that the amplitude of beam sea condition is the most severe followed by the bow and quarter seas conditions. The peaks of the roll motions are also different from each incident wave heading angle. The trimaran has a lower peak amplitude in the quarter sea, however, in the beam and bow sea, the trimaran shows slightly higher and indicates a slight phase difference than the monohull. The tendency of roll amplitude in the forward speed is consistent with other incident waves of the following and head seas, where the motion amplitude of the trimaran tends to be worse around the head seas, which is caused by the different hull forms. Although the different amplitudes between trimaran and monohull are slight in wave conditions however concerning the static stabilities of the ship large-angle stabilities in Subsection 4.1 and shown in Figure 4 it is convenient to envisage the overall stability characteristics of the trimaran and monohull.
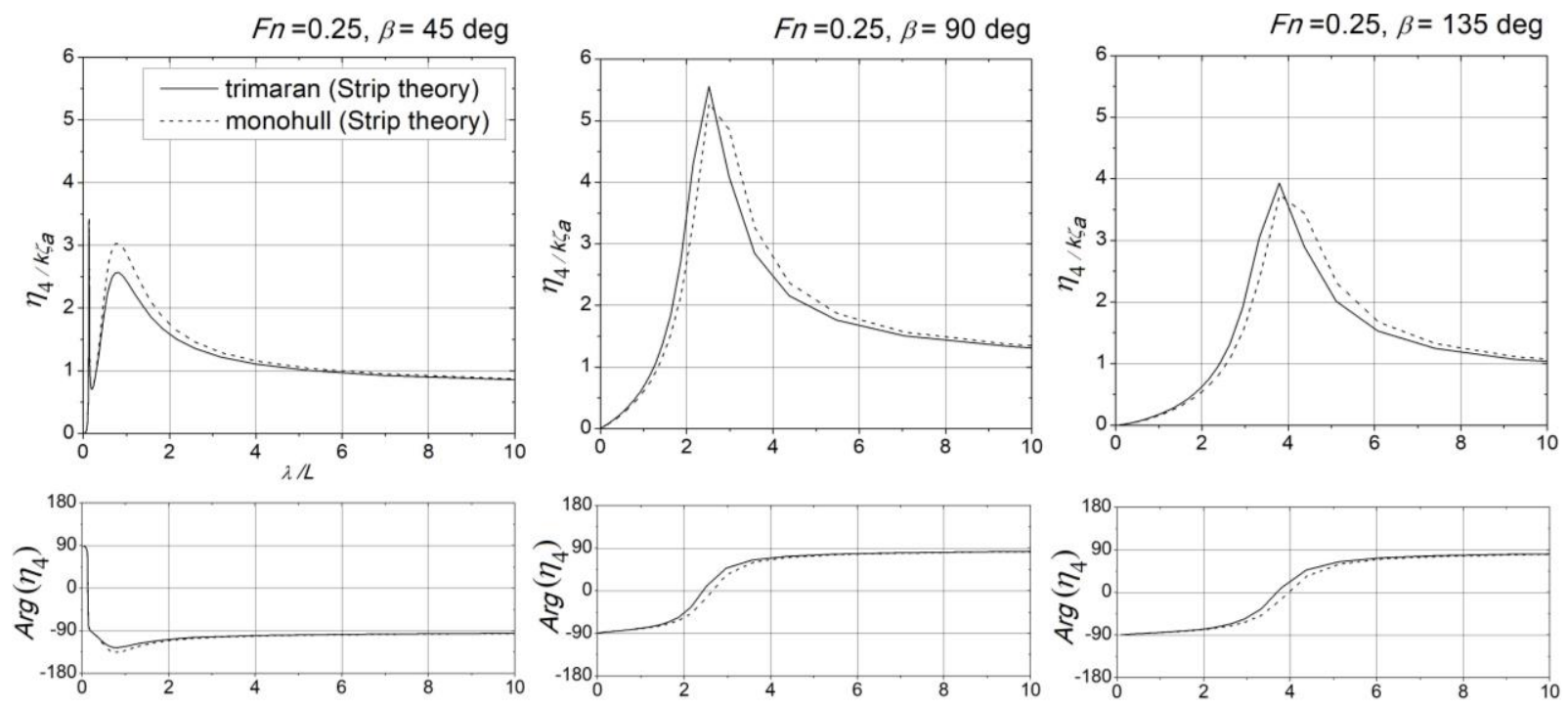

Fig. 11. Roll RAOs of the trimaran and monohull at $F n=0.25$ in quarter, beam and bow seas

\subsection{Ship Resistances}

The calm water resistance computation based on the analytical slender body method was made for the ship speed ranges of $F n=0-0.5$ as shown in Table 2. Although the ship service speed is $\mathrm{Fn}=0.25$ and the maximum allowable speed is at $\mathrm{Fn}=0.35$, we can see the trimaran shows better in total resistance below the inflection point of $\mathrm{Fn}=0.27$ compare to the monohull, however, we can see the deterioration of trimaran performance at a high speed over $\mathrm{Fn}=0.27$. It might be regarded as the semi trimaran design of the hull form that may result in worse performance at high speed than the monohull.

The computation of added wave resistances is made for the forward speed of $\mathrm{Fn}=0.25$ and $\mathrm{Fn}=0.35$ in the significant amplitude of resistance in head sea conditions based on the heave and pitch motions in waves. As shown in Figure 12, the amplitudes of added resistances are shown in non-dimensional values and both the trimaran and monohull seem not significant differences even with the difference of forward speed. The peak values are observed at around the $\lambda / L=1.5-2.0$. From this result, we may understand the range of frequencies around $\lambda / L=1.0-3.0$ when the resistances due to waves are significant in conjunction with the steady resistance of calm water at the corresponding speeds of $\mathrm{Fn}=0.25$ and $\mathrm{Fn}=0.35$. 
Table 2

Calm water resistances of the trimaran and monohull fishing vessels

\begin{tabular}{|c|c|c|c|c|c|}
\hline Speed & $\mathrm{Fn}$ & $\begin{array}{l}\text { Total Resistance } \\
\left(\mathrm{R}_{\mathrm{T}}\right)\end{array}$ & $\begin{array}{l}\text { Total Resistance } \\
\left(R_{T}\right)\end{array}$ & $\begin{array}{l}\text { Total Resistance } \\
\left(R_{T}\right)\end{array}$ & $\begin{array}{l}\text { Total Resistance } \\
\left(R_{T}\right)\end{array}$ \\
\hline $\mathrm{m} / \mathrm{s}$ & & $\begin{array}{l}\mathrm{kN} \\
\text { trimaran (exp) }\end{array}$ & $\begin{array}{l}\mathrm{kN} \\
\text { trimaran (slender } \\
\text { body) }\end{array}$ & $\begin{array}{l}\text { kN } \\
\text { monohull (exp) }\end{array}$ & $\begin{array}{l}\text { kN } \\
\text { monohull } \\
\text { (slender body) }\end{array}$ \\
\hline 0.2 & 0.012 & 0 & 0 & 0 & 0 \\
\hline 1.8 & 0.108 & 4.6 & 5.1 & 9 & 10.9 \\
\hline 2.6 & 0.156 & 10 & 11.6 & 15 & 16.3 \\
\hline 3.4 & 0.204 & 11.5 & 11.9 & 18 & 19 \\
\hline 3.8 & 0.228 & 22 & 25.2 & 23 & 25 \\
\hline 4.2 & 0.252 & 23 & 22.1 & 24 & 24.7 \\
\hline 4.6 & 0.276 & 41 & 42.9 & 36 & 36.4 \\
\hline 5 & 0.3 & 61 & 63 & 48.5 & 50.8 \\
\hline 5.8 & 0.348 & 58 & 56.5 & 46.5 & 47.2 \\
\hline 6.8 & 0.408 & 74 & 72 & 58.5 & 59.4 \\
\hline 7.6 & 0.456 & 97 & 95.5 & 77 & 77.9 \\
\hline
\end{tabular}
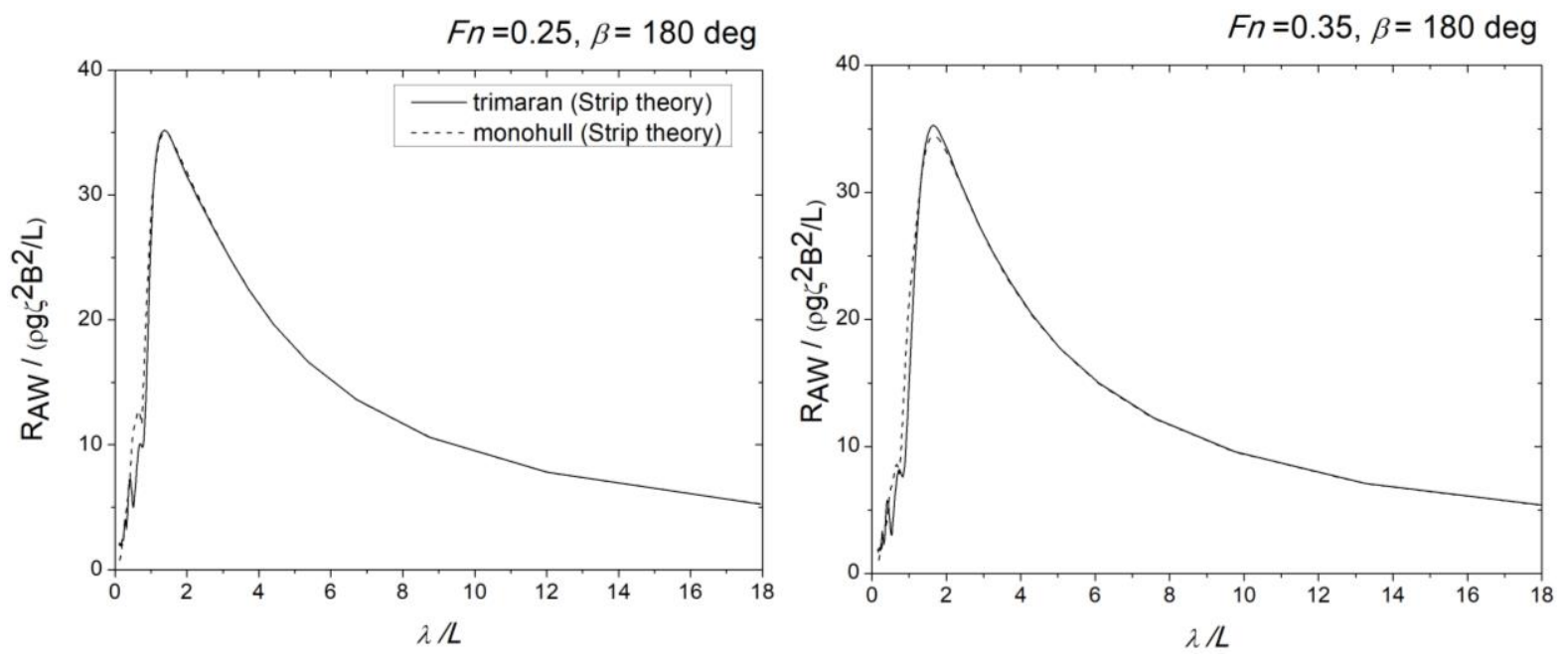

Fig. 12. Added wave resistances of the trimaran and monohull fishing vessel

\section{Conclusions}

In this paper, we propose a design of trimaran hull form fishing vessel in comparison to a monohull fishing vessel with similar ship particulars i.e., the displacement, the vertical center of gravity, and the gyration radius of inertia. The linear strip theory program was used to compute the ship motion RAOs of heave, pitch, roll, whereas, the added wave resistances were computed based on the heave and pitch motions. Heave and pitch motions were computed for the cases of zero and forward speed cases of $F n=0.25$ and $F n=0.35$ in the following and head seas. The results show the trimaran has lower amplitudes of heave and pitch than monohull at zero speed in following and head sea conditions and at the forward speeds of the following sea. Meanwhile, at the forward speeds of the head sea, the trimaran has a similar or does not seem to be better than monohull even around the resonance frequency ranges. Roll motions were computed for the forward speed $\mathrm{Fn}=0.25$ in the quarter, beam, and bow seas. The results show the trimaran and monohull do not differ a lot in roll motions and the peak roll amplitude of beam sea condition shows a reasonable result. In addition, the large-angle stabilities show the trimaran has much better intact stability than the monohull. A large GZ-length difference of almost twice from the monohull showing much better initial-stability of 
the trimaran. However, for the seakeeping results, we note that the computation accuracy of the forward speed case is not as good as the zero speed. The steady calm water resistances were computed by means of analytical slender body method for a range of ship speeds. The results show the trimaran has better steady resistance than monohull up to $\mathrm{Fn}=0.27$ and becomes deteriorate over this speed. The added resistances computed from the heave and pitch motions in ship service speed $\mathrm{Fn}=0.25$ show no significant differences for trimaran and monohull with the considerable amplitude of added resistances around $\lambda / L=1.0-3.0$. As a concluding remark, at the initial design stage, the linear strip theory method is considered to be appropriate in terms of time efficiency and computation accuracy to some extent. However, to assess the accuracy of motion resonances and forward speeds, hence in some particular cases the authors recommend comparing the computation with other computation methods such as the panel method or CFD for better accuracy.

\section{Acknowledgement}

This research was funded by a grant from the University of Indonesia (Hibah UI Jurnal Q3 No.NKB2016/UN2.RST/HKP.05.00/2020)

\section{References}

[1] Tuck, Ernest O., and Leo Lazauskas. "Optimum hull spacing of a family of multihulls." Ship Technology ResearchSchiffstechnik 45, no. 4 (1998): 180-195.

[2] Yeung, Ronald W. "Interference Resistance of Multi-hulls per thin-ship theory." In 20th International Workshop on Water Waves and Floating Bodies, Longyearbyen, Spitsbergen. 2005.

[3] Insel, M., and A. F. Molland. "An investigation into the resistance components of high speed displacement catamarans." Transactions of The Royal Institution of Naval Architects, RINA, Volume 133, 1991. (1991).

[4] Seif, MS, and E. Amini. "Performance Comparision Between Planing Monohull And Catamaran At High Froude Numbers." Iranian Journal of Science \& Technology 28, no. B4 (2004).

[5] Boote, D., T. Colaianni, and E. Pino. "Seakeeping analysis of a trimaran fast ferry." In 4th Int. Conf. High-Performance Marine Vehicle (HIPER), pp. 304-316. 2004.

[6] Ackers, Benjamin B., Thad J. Michael, D. Andrews, BL Hutchison, and OW Tredennick. "An investigation of the resistance characteristics of powered trimaran side-hull configurations. Discussion. Authors' closure." TransactionsSociety of Naval Architects and Marine Engineers 105 (1997): 349-373.

[7] Xu, H., and Z. Zou. "Numerical prediction of wave-making resistance of a trimaran." In Proc. 2nd Int. Workshop on Ship Hydrodynamics (IWSH'01), China, pp. 105-109. 2001.

[8] Doctors, Lawrence J. "The optimisation of trimaran sidehull position for minimum resistance." In Proceedings of the 7th International Conference on Fast Sea Transportation, FAST2003, Ischia, Italy, ISBN: 99-901174-0-0 (set). Paper: P2003-7 Proceedings. 2003.

[9] Degiuli, Nastia, Andreja Werner, and Igor Zotti. "An Experimental Investigation into the Resistance Components of Trimaran Configurations." In FAST 2005-St. Petersburg-Russia, vol. 400, pp. 1-8. IMarEst, 2005.

[10] Maynard, T., P. K. Sahoo, J. Mikkelsen, and D. McGreer. "Numerical and experimental study of wave resistance for trimaran hull forms." In HIPER 08: 6th International Conference on High Performance Marine Vehicles, vol. 1, pp. 117-132. 2008.

[11] Hafez, Khaled, and Abdel-Rahman El-Kot. "Comparative analysis of the separation variation influence on the hydrodynamic performance of a high speed trimaran." Journal of Marine Science and Application 10, no. 4 (2011): 377-393. https://doi.org/10.1007/s11804-011-1083-0

[12] Zhang, Bao-ji, Kun Ma, and Zhuo-shang Ji. "The optimization of the hull form with the minimum wave making resistance based on Rankine source method." Journal of Hydrodynamics 21, no. 2 (2009): $277-284$. https://doi.org/10.1016/S1001-6058(08)60146-8

[13] Wang, Zhong, and Xiao-ping Lu. "Numerical simulation of wave resistance of trimarans by nonlinear wave making theory with sinking and trim being taken into account." Journal of Hydrodynamics 23, no. 2 (2011): $224-233$. https://doi.org/10.1016/S1001-6058(10)60107-2

[14] Xu, Min, and Shi-lian Zhang. "A numerical study on side hull optimization for trimaran." Journal of Hydrodynamics 23, no. 2 (2011): 265-272. https://doi.org/10.1016/S1001-6058(10)60112-6

[15] Salvesen, Nils, E. O. Tuck, and Odd Faltinsen. "Ship Motions and Sea Loads." Published in Transactions of Society of Naval Architects and Marine Engineers (1970): 250-287. 
[16] MaxSurf. Maxsurf Motions. Windows Version 20 User Manual. Bentley Systems, Inc. (2015).

[17] MaxSurf. Maxsurf Stabilities. Windows Version 20 User Manual. Bentley Systems, Inc. (2015).

[18] MaxSurf. Maxsurf Resistances. Windows Version 20 User Manual. Bentley Systems, Inc. (2015).

[19] Bishop, Richard Evelyn Donohue, Richard ED Bishop, and W. G. Price. Hydroelasticity of ships. Cambridge University Press, 1979.

[20] Skejic, Renato. "Maneuvering and seakeeping of a single ship and of two ships in interaction." PhD diss., Department of Marine Technology, Faculty of Engineering Science and Technology, Norwegian University of Science and Technology, Trondheim, Norway (2008).

[21] Wellicome, J. F., P. Temarel, A. F. Molland, and P. R. Couser. "Experimental measurements of the seakeeping characteristics of fast displacement catamarans in long-crested head-seas." Southampton, UK. (Ship Science Reports, 89). University of Southampton (1995).

[22] Gerritsma, J. "Shipmotions in longitudinal waves." International Shipbuilding Progress 7, no. 66 (1960): $49-71$. https://doi.org/10.3233/ISP-1960-76601

[23] Sclavounos, Paul D., David C. Kring, Yifeng Huang, Demetrios A. Mantzaris, Sungeun Kim, and Yonghwan Kim. "A computational method as an advanced tool of ship hydrodynamic design." Society of Naval Architects and Marine Engineers Transactions, Volume 105, pp. 375-397 (1997).

[24] Ghamari, Isar, Odd M. Faltinsen, and Marilena Greco. "Investigation of parametric resonance in roll for container carrier ships." In International Conference on Offshore Mechanics and Arctic Engineering, vol. 56598, p. V011T12A044. American Society of Mechanical Engineers, 2015. https://doi.org/10.1115/OMAE2015-41528

[25] Journée, J. M. J. "Verification and validation of ship motions program SEAWAY." Delft University of Technology Shiphydromechanics Laboratory, Report1213a (2001).

[26] Vugts, Jan H. "Cylinder motions in beam waves." TUDelft, Faculty of Marine Technology, Ship Hydromechanics Laboratory Report 207-P, Nederlands Scheepsstudiecentrum TNO, Shipbuilding Department, Delft, The Netherlands, Report 115 S (1968).

[27] Vugts, Jan H. "The hydrodynamic coefficients for swaying, heaving and rolling cylinders in a free surface." International Shipbuilding Progress 15, no. 167 (1968): 251-276. https://doi.org/10.3233/ISP-1968-1516702

[28] Kato, Hiroshi. "On the frictional resistance to the rolling of ships." Journal of Zosen Kiokai 102 (1958): 115. https://doi.org/10.2534/ijasnaoe1952.1957.102 115

[29] Tanaka, Norio. "A study on the bilge keels part 4. on the eddy-making resistance to the rolling of a ship hull." Journal of Zosen Kiokai 1961, no. 109 (1961): 205-212. https://doi.org/10.2534/ijasnaoe1952.1961.205

[30] Tuck, E. O., L. Lazauskas, and D. C. Scullen. "Sea Wave Pattern Evaluation, Part 1 report: Primary code and test results (surface vessels)." Applied Mathematics Department, University of Adelaide (1999).

[31] Couser, Patrick. "An investigation into the performance of high-speed catamarans in calm water and waves." $P h D$ diss., University of Southampton, 1996.

[32] Michell, John Henry. "XI. The wave-resistance of a ship." The London, Edinburgh, and Dublin Philosophical Magazine and Journal of Science 45, no. 272 (1898): 106-123. https://doi.org/10.1080/14786449808621111

[33] Salvesen, Nils. "Added resistance of ships in waves." Journal of Hydronautics 12, no. 1 (1978): $24-34$. https://doi.org/10.2514/3.63110 